\title{
0 discurso de ódio na clínica psicanalítica
}

\author{
Hate speech in psychoanalytic clinic
}

El discurso de odio en la clínica psicoanalítica

\author{
Recebido: 08/08/2020 \\ Aprovado: 05/01/2021 \\ Publicado: 18/04/2021
}

\author{
Mariana de Toledo Nascimento Gomes ${ }^{1}$
}

Esta é uma revisão narrativa realizada entre 2018 e 2020, por influência do cenário mundial, com o objetivo de analisar os fenômenos de discurso de ódio e suas manifestações em articulação com a teoria psicanalítica, bem como o manejo no âmbito da clínica. À luz da teoria freudiana, exploram-se as possíveis motivações inconscientes daqueles que proferem o discurso do ódio e busca-se identificar seus impactos na saúde psíquica de seus alvos. Três áreas temáticas são trazidas para o debate, a saber: $O$ discurso de ódio na sociedade, Discurso de ódio e psiquismo e $O$ discurso de ódio na clínica psicanalítica. São inúmeros os discursos de ódio ao longo da história, que não parecem perder potência mesmo diante de uma realidade social em que são amplamente questionados e condenados. Essa persistência do discurso se encontra justificada nas hipóteses freudianas sobre os impulsos destrutivos inerentes ao ser humano, seus recursos de identificação e suas moções narcísicas. A teoria psicanalítica traz à luz as origens do desejo humano de destruição e revela uma constatação indigesta: não é possível se livrar completamente desse desejo. Por meio da psicanálise, tem-se a busca por saídas mais saudáveis a esses impulsos, identificações e motivações narcísicas, já que sua exacerbação é potencialmente causadora de adoecimento psíquico - além de poder culminar na real aniquilação desses tantos "outros".

Descritores: Psicanálise; Agressão; Ódio; Angústia psicológica.

This is a narrative review carried out between 2018 and 2020, influenced by the global context. It aims to analyze the hate speech phenomena and its manifestations in conjunction with psychoanalytic theory, as well as management within the clinic. From the perspective of the Freudian theory, the possible unconscious motivations of those who utter hate speech are explored and an attempt is made to identify their impacts on the mental health of their targets. Three thematic areas are brought into the debate, namely: Hate speech in society, Hate speech and the psyche and Hate speech in the psychoanalytic clinic. There are countless hate speeches throughout history, which do not seem to lose power even in a social reality in which they are widely questioned and condemned. This persistence of the discourse is justified in the Freudian hypotheses about the destructive impulses inherent to the human being, their resources of identification and their narcissistic motions. Psychoanalytic theory brings to light the origins of the human desire for destruction and reveals an indigestible notion: it is not possible to get rid of that desire completely. Through psychoanalysis, there is a search for healthier ways out of these narcissistic impulses, identifications and motivations, since their exacerbation is potentially causing psychic illness - in addition to the possibility of culminating in the real annihilation of these so many "others".

Descriptors: Psychoanalysis; Aggression; Hate; Psychological distress.

Esta es una revisión narrativa realizada entre 2018 y 2020, por influencia del escenario global, con el objetivo de analizar los fenómenos del discurso de odio y sus manifestaciones en articulación con la teoría psicoanalítica, así como el manejo en el ámbito clínico. A la luz de la teoría freudiana, son exploradas las posibles motivaciones inconscientes de quienes emiten discursos de odio y se trata de identificar sus impactos en la salud psíquica de sus destinatarios. Se aportan al debate tres áreas temáticas, a saber: $E l$ discurso de odio en la sociedad, Discurso de odio y el psiquismo y El discurso de odio en la clínica psicoanalítica. Existen innumerables discursos de odio a lo largo de la historia, que no parecen perder potencia ni siquiera ante una realidad social en la que son ampliamente cuestionados y condenados. Esta persistencia del discurso se justifica en las hipótesis freudianas sobre los impulsos destructivos inherentes al ser humano, sus recursos de identificación y sus conductas narcisistas. La teoría psicoanalítica saca a la luz los orígenes del deseo humano de destrucción y revela una constatación indigesta: no es posible deshacerse completamente de este deseo. A través del psicoanálisis, se buscan salidas más sanas a estos impulsos, identificaciones y motivaciones narcisistas, ya que su exacerbación es potencialmente causa de enfermedad psíquica - además de poder culminar en la aniquilación real de tantos "otros".

Descriptores: Psicoanálisis; Agresión; Odio; Distrés psicológico.

1. Bacharel em Letras - Habilitação em Inglês. Psicanalista. Pós-graduanda em Psicanálise pelo Núcleo Brasileiro de Pesquisas Psicanalíticas. Especializanda em Psicanálise na Parentalidade e Perinatalidade pelo Instituto Gerar de Psicanálise, São Paulo, SP, Brasil. ORCID: 0000-0002-0159-554X E-mail: marianatoledo.psi@gmail.com 


\section{INTRODUÇÃO}

$\mathbf{0}$ discurso de ódio permeia a história da humanidade com notável persistência e universalidade, assumindo configurações diversas de acordo com as questões mais marcantes de cada época ou contexto, porém sempre fundamentado em princípios análogos, pela qual seus alvos são vistos como uma ameaça que precisa ser eliminada.

Revela-se, portanto, como uma das manifestações dos impulsos destrutivos que Freud há muito identificou como inerentes à natureza humana, configurando um empecilho para a vida em sociedade. Entretanto, contrariando o discurso religioso e o senso comum, que tendem a pregar o amor ao próximo como uma obrigação moral, postula-se que esses impulsos agressivos, paradoxalmente, também têm um grau de importância para a manutenção da integridade do próprio sujeito, tornando o caminho para o amor ao próximo mais tortuoso do que se possa imaginar ${ }^{1}$.

A cultura e os diversos formatos de relações que marcam a inserção do ser humano na civilização interferem na experiência intrapsíquica do sujeito, assim como aspectos inerentes ao psiquismo não apenas pautam a realidade subjetiva, mas podem se manifestar como fenômenos sociais ${ }^{1}$. Aponta-se, portanto, uma relação dialética entre o sujeito e seu entorno.

0 discurso de ódio, independentemente de sua forma, tem seu conteúdo enraizado em motivações inconscientes. Assim, é válido considerar que tais motivações possam ser reveladas no divã, bem como seus efeitos na subjetividade de seus alvos - especialmente quando se considera que esses costumam pertencer a grupos sociais sistematicamente hostilizados, potencialmente resultando em sofrimentos psíquicos próprios a essa vivência.

A considerar a patente contemporaneidade do discurso de ódio, faz-se relevante explorar como os sujeitos podem ser motivados ou afetados por ele e, a partir disso, explorar maneiras de se abordar o fenômeno no contexto da clínica psicanalítica. Assim, este artigo tem como objetivo analisar os fenômenos de discurso de ódio e suas manifestações em articulação com a teoria psicanalítica, e o manejo no âmbito da clínica.

\section{MÉTODO}

Esta é uma revisão narrativa da teoria psicanalítica, para uma exploração do fenômeno social denominado discurso de ódio e das experiências clínicas dele decorrentes.

Inicia-se com uma descrição do conceito de discurso de ódio, identificando seus entendimentos mais comuns na sociedade e citando alguns exemplos históricos, para contextualizá-lo. À luz da teoria freudiana, explora-se as possíveis motivações inconscientes daqueles que proferem esse discurso e busca identificar seus impactos na saúde psíquica de seus alvos.

Para isso, recorre a conceitos como o narcisismo primário e a pulsão de morte, bem como obras freudianas que tratam de fenômenos coletivos, como e 0 Mal-estar na Civilização ${ }^{1}$ e, Psicologia das Massas e Análise do $\mathrm{Eu}^{2}$ dispondo também de contribuições de autores contemporâneos. E, ainda, traz as questões da clínica psicanalítica e do papel do analista diante desse discurso ou de seus efeitos.

Este estudo foi desenvolvido em meados de 2020, considerando a escalada explícita do discurso de ódio no cenário mundial, com destaque para os eventos políticos globais testemunhados ao longo da década de 2010.

\section{RESULTADOS}

Esta revisão se apoia em 21 referencias e traz três áreas temáticas para o debate, a saber: o discurso de ódio na sociedade, Discurso de ódio e psiquismo; e, $O$ discurso de ódio na clínica psicanalítica. 


\section{DISCUSSÃO}

\section{O discurso de ódio na sociedade}

0 conceito "discurso de ódio" deriva da expressão na língua inglesa hate speech, que já é dicionarizada nesse idioma, tendo se tornado um conceito discutido universalmente. 0 dicionário Oxford da língua inglesa define o termo como "discurso oral ou escrito que seja abusivo ou ameaçador e expresse preconceito contra um grupo específico, principalmente com relação à raça, religião ou orientação sexual"3.

Em relatório elaborado para uma conferência sobre o tema no Conselho da Europa, organização europeia voltada para a defesa dos direitos humanos, da democracia e do Estado de Direito, McGonagle ${ }^{4}$ traz a seguinte explicação:

[...] qualquer expressão que dissemine, incite, promova ou justifique o ódio racial, a xenofobia, o antissemitismo ou qualquer outra forma de intolerância, incluindo a intolerância causada por nacionalismo agressivo e etnocentrismo, discriminação $e$ hostilidade contra minorias, migrantes e pessoas de origem estrangeira.

No Brasil, em periódico oficial do Senado Federal, tem-se como possíveis alvos: "opinião política [...], posição socioeconômica, nível educacional [...] característica genética, estado de saúde física ou mental [...], ou qualquer outra condição" ${ }^{\prime 5}$.

Essas definições demonstram que o discurso de ódio não configura uma agressão aleatória. Ele visa a alvos específicos, normalmente escolhidos por sua diferença em relação àquele que o profere, e surge a partir da construção de narrativas que sirvam como justificativa, ainda que ilusória e exclusivista, para a subjugação de tais alvos. São narrativas pautadas por um extremismo e uma intencionalidade que fogem à normalidade das variadas expressões de afetos humanos.

Os ideais que sustentam o discurso de ódio estão engendrados no tecido social, determinando o modo de agir de certos grupos da sociedade, organizados ou não. Assim, o afeto "ódio" se materializa por meio da linguagem, inserindo-se na forma de um conjunto de valores, no registro simbólico que dita tanto as relações entre os sujeitos quanto aquilo que cada um se percebe capaz de tolerar.

Um exemplo histórico clássico é o ódio fomentado contra diversos grupos sociais no regime nazista (paradigmaticamente, o povo judeu, mas também os ciganos, poloneses, soviéticos, asiáticos, deficientes físicos, deficientes mentais, homossexuais e miscigenados, e outros), que os caracterizava como uma grande ameaça a ser combatida. Essa ideia era reforçada e repetida ad nauseam nos discursos de seus líderes. 0 Terceiro Reich evidenciou como esse tipo de discurso pode rapidamente sair do campo dos afetos e se materializar na realidade da vida cotidiana, inclusive na forma de leis.

Na história ocidental recente, outros casos emblemáticos de normas e leis ativamente sustentadas por discursos de ódio incluem as leis de Jim Crow, nos Estados Unidos, e o apartheid, na África do Sul, ambos regimes que decretavam a segregação social de pessoas negras e outras pessoas não brancas, privando-lhes de direitos básicos garantidos à população branca e sujeitando-os a inúmeros episódios de violência6-7.

Há também países que consideram crime a homossexualidade ${ }^{8}$, inclusive sujeito à pena de morte, ou que limitam os direitos de seus cidadãos homossexuais, proibindo o casamento entre pessoas do mesmo sexo e a adoção de crianças por casais homoafetivos. Também, o discurso de ódio a estrangeiros costuma se destacar, principalmente, diante das ondas de imigração, tendo ganhado força nos últimos anos - com destaque para os ataques a cidadãos de origem islâmica, configurando o que se denomina atualmente de islamofobia.

Muitos outros contextos do discurso de ódio poderiam ser citados. Entretanto, esses são suficientes para demonstrar o traço comum presente em sua retórica: as raças não brancas representariam uma "ameaça à supremacia 'natural' dos brancos"; a homossexualidade representaria uma "ameaça à perpetuação da espécie"; as mulheres representariam uma "ameaça à superioridade do homem"; os imigrantes iriam "acabar com nossos empregos $e$ 
destruir nossa pátria"; e assim por diante. Evidencia-se, portanto, uma lógica tipicamente paranoica.

\section{Discurso de ódio e psiquismo}

Na teoria freudiana, o ódio surge como afeto primordial para a própria constituição do sujeito, ganhando potência na fase de vida de bebê em que o mundo externo é vivenciado como uma ameaça à sua sobrevivência, denominada "narcisismo primário" 9 . Nessa fase, o bebê investe toda sua libido (energia vital) em si próprio, um movimento psíquico necessário para que ele possa se perceber enquanto indivíduo. Entretanto, esse excesso de investimento narcísico faz com que o mundo externo lhe pareça extremamente estranho e ameaçador, e assim ele o odeia.

Diz Freud em Os Instintos e Seus Destinos 10: "sentimos a 'repulsão' do objeto e o odiamos; e esse ódio pode então se exacerbar em propensão a agredir o objeto, em intenção de aniquilá-lo", sendo o objeto aquilo que faz parte do mundo externo. Nesse sentido, o ódio surge antes da capacidade de amar, que se desenvolve quando o sujeito passa a introjetar objetos em seu próprio psiquismo. Com essa introjeção, o mundo externo deixa de ser totalmente insólito, dividindo-se em "uma parte prazerosa (introjetada) e outra estranha"10. Essa dinâmica estabelece uma relação de ambivalência entre amor e ódio que perdurará ao longo da vida do sujeito.

Posteriormente, desenvolve-se o conceito de pulsão de morte, que diz respeito a moções inconscientes caracterizadas por buscar, constantemente, a repetição, abarcando as disposições agressivas do psiquismo ${ }^{11}$. Essas moções teriam como meta primordial a eliminação de tensões e perturbações psíquicas; assim, todo ser humano teria uma disposição agressiva inata e importante para sua sobrevivência. A partir daí, passa-se a considerar na teoria psicanalítica uma dinâmica pulsional entre pulsão de vida e pulsão de morte, para além dos movimentos narcísicos.

Já Green ${ }^{12}$, sugere que o narcisismo primário seja pensado não apenas como uma fase da constituição humana que, após concluída, é integralmente superada, mas sim como uma instância psíquica que permanece "ativa" ao longo da vida, em maior ou menor medida. Seria, assim, uma condição que nunca, de fato, abandona o sujeito: uma estrutura, e uma defesa anterior ao recalcamento ${ }^{12}$. Remetendo à concepção apresentada em $O$ Eu e o $I^{13}$ se defende que tudo o que é originário no psiquismo nunca deixa de fazer parte dele.

Os recursos psíquicos próprios do narcisismo primário ficariam sempre disponíveis para os processos de ligação pulsional, podendo servir à tendência destrutiva da pulsão de morte na forma de intenção de "aniquilar" objetos percebidos como estranhos. A fantasia paranoica do discurso de ódio aponta justamente para essa "estranheza" entre sujeito e objeto, revelando uma incapacidade de se sustentar diante das diferenças presentes nas relações intersubjetivas, ou, em outras palavras: "o trato social afasta as igualdades e instala a estranheza"14.

0 ódio se perpetua como mediador dos pactos formados no tecido social a partir de identificações narcísicas, remetendo ao que há de mais primário no aparelho psíquico, o que explica a persistência do discurso de ódio ao longo da história - que requer tanto um excesso de identificação com semelhantes quanto um excesso de estranhamento das diferenças. Por intermédio desses pactos, os grupos se unem para pregar ou efetivar a exterminação de outros que, em sua fantasia, ameacem sua existência e integridade.

\section{o discurso de ódio na clínica psicanalítica}

Podem-se pontuar dois espectros principais de manifestação do discurso de ódio na clínica: o sujeito que propaga o discurso e o sujeito que é vítima dele. Essa divisão não significa que um mesmo sujeito não possa desempenhar ambos os papéis, especialmente considerando o caráter estrutural que localiza a racionalidade desse discurso na sociedade e a complexidade da manifestação psíquica do ódio. Estes dois polos não abarcam as possíveis "zonas cinzentas". 
Partindo desses dois espectros, há de se considerar que indivíduos fortemente identificados com discursos de ódio bem estruturados e delimitados, especialmente aqueles que se vinculam a organizações de grupo, provavelmente configurem uma parcela reduzida das pessoas que buscam o consultório de um psicanalista. Isso pode ocorrer tanto pelo fato de a própria psicanálise ser alvo de alguns desses grupos (não à toa os livros da teoria freudiana foram queimados pelo regime nazista), quanto pelo fato de que indivíduos que se encontram em tamanha identificação com essas organizações costumam obter delas grande satisfação narcísica, fundamentada em um senso de pertencimento que não deixa espaço para autoquestionamentos.

Em Psicologia das Massas e Análise do $E u^{2}$, postula-se que os grupos acabam por desempenhar um papel integrador para o sujeito, na medida em que o investimento de energia psíquica destinado a objetos externos é direcionado às próprias relações de grupo, reforçando os investimentos narcísicos. A descarga pulsional que esse sujeito obtém nos discursos e atos violentos e nas relações identificatórias pode acabar por mascarar qualquer tipo de sofrimento ou limitação decorrente da incapacidade de se vincular ao outro, tolerar o diferente e sustentar a alteridade.

Para o sujeito acometido pelo discurso do ódio que deseje trabalhar suas questões no divã, a análise lhe oferecerá a possibilidade de formar identificações mais saudáveis, sublimar seus instintos destrutivos, e identificar a fragilidade e inviabilidade de alguns ideais, buscando pavimentar caminhos em direção a ideais de si e do outro que tragam menos obstáculos à sua própria vida e à sua inserção na sociedade.

Isso não será possível se o psicanalista se prender ao senso comum que reforça os conflitos superegóicos, como a exigência de amor ao próximo como uma obrigação moral. Isto pois, a idealização da natureza humana como inerentemente bondosa gera "estranhamentos frente à retórica do ódio", podendo trazer ruídos de julgamento à escuta ${ }^{15}$.

Nesses casos, certamente o psicanalista também precisaria ficar atento às manifestações dos impulsos destrutivos na própria transferência, e alguns fatores pessoais podem pesar mais do que com pacientes que não apresentem um apreço particular por esse tipo de discurso. Assim, como se daria, por exemplo: A relação transferencial entre um psicanalista negro e um analisando fortemente identificado com discursos racistas?

No outro espectro - aqueles que são alvos do discurso violento -, pode-se pensar que, se a psicanálise ensina que o ser humano se constitui enquanto sujeito a partir do olhar do outro, o discurso de ódio evidencia que esse olhar pode vir carregado de negatividade. Ainda que não venham acompanhadas de atos violentos, as narrativas fundamentadas no "ódio ao outro" são suficientes para criar condições para uma experiência traumática do sujeito-alvo, levando a autopercepções de inferioridade, impotência, inadequação e vulnerabilidade. Isso se potencializa pelo fato de que aquilo que é odiado é algo constitutivo do sujeito, sendo imutável e irremovível (nacionalidade, sexualidade, raça, e outros).

Tomando o discurso racista, Nogueira16 discorre que "o significante 'cor negra' está inserido, evidente, num arranjo semântico, político, econômico e histórico". A cor da pele, portanto, figura entre os diversos significantes que constituem as representações simbólicas engendradas na cultura. Sendo assim, para além dos impactos que costumam ser objeto de estudo sociológico (falta de oportunidade, maior vulnerabilidade social, menor renda), carrega consigo implicações subjetivas profundas.

Diante disso: Como dimensionar o sofrimento causado por um discurso que diz que o sujeito não é bem-vindo, que é diferente, que é inferior? Ou por leis e regras sociais que decretam que alguém deve ter menos direitos, ou até ser morto, por ser quem é? A partir dos referidos arranjos semânticos, o próprio discurso se torna a munição. Já as feridas causadas são usadas como munição extra, frequentemente sendo reduzidas a "delírios persecutórios" por aqueles que atacam, o que só faz reforçar o impacto psíquico negativo. 
Tudo isso corrobora a potencialidade traumática desse tipo de discurso. Pereira ${ }^{17}$ ressalta que "o traumático se instala na esfera do inacessível, algo encriptado", sem qualquer tipo de simbolização, sendo sentido pelo sujeito como algo estrangeiro a si mesmo, restando-lhe a angústia. Laplanche e Pontalis ${ }^{18}$ afirmam que o trauma "se define [...] pela incapacidade em que se encontra o sujeito de reagir a ele de forma adequada".

Outra proposição teórica importante acerca do trauma é a de que este se dá quando o entorno promove a negação ou o não reconhecimento de uma experiência vivida pelo sujeito que se dá seu caráter traumático, como no caso de crianças que sofrem abuso sexual e, ao relatarem o acontecido, ouvem dos adultos que aquilo não tem importância ou nunca aconteceu $^{19}$. Isso faz com que a criança chegue a questionar sua própria vivência e a legitimidade de sua angústia.

Essa formulação reforça o papel do não reconhecimento na equação do sofrimento psíquico decorrente de situações traumáticas, sendo evidenciada na dinâmica do discurso de ódio. Isso ocorre, quando qualquer tentativa de denunciar esse discurso é tachada de exagero ou mentira sem maior aprofundamento. Essa negação, combinada à incapacidade do sujeito de nomear a violência sofrida e os afetos deflagrados por ela, tem como consequência um grande conflito psíquico, possivelmente resultando em um excesso pulsional que, sem encontrar vazão simbólica, pode gerar um sofrimento atroz.

Já Ocariz ${ }^{20}$ destaca que, para a psicanálise, "o traumático é aquilo que retorna e está ligado à repetição", ou seja, vincula-se diretamente à dinâmica da pulsão de morte. Uma das consequências disso seria uma espécie de imobilização do sujeito, que diante da flagrante inferiorização se vê incapaz de ocupar o lugar de sujeito desejante, sustentando-se em um lugar mortificado. Nesta perspectiva surgem os quadros mais graves de depressão e ideações suicidas.

Outro possível efeito do trauma seria a tentativa de ressignificação da cena traumática pelo mecanismo de identificação com o agressor, em que a única saída encontrada pelo psiquismo do sujeito para lidar com o desamparo e a ameaça de não sobrevivência diante do trauma é identificar-se com aquele que o perpetrou, tornando-se como ele. A agressão recebida é deslocada para algum outro discurso violento proferido pelo próprio alvo, numa tentativa de preservar um $E u$ despedaçado. $O$ sujeito que introjeta a figura de seu algoz pode, inclusive, se submeter a uma espécie de autorrejeição, cuja violência psíquica pode ser igualmente arrebatadora.

De qualquer maneira, seja o sujeito que desloca seu ódio para figuras terceiras ou aquele que, atormentado pela marginalização, direciona sua força pulsional à destruição de si próprio, é preciso que seu sofrimento seja dialetizado para que possa ser ressignificado e despotencializado, permitindo que seus impulsos mais primários sigam por vias mais saudáveis para o próprio sujeito e para seu entorno:

A falta de verdade abre caminho para a repetição como sintoma social. Romper com a compulsão à repetição significa poder falar e escutar as várias versões sobre o acontecido, admitindo-se a multiplicidade de versões ${ }^{2}$.

Diante disso, é importante que o analista atue como testemunha, reconhecendo os efeitos do trauma e criando condições para que o analisando os nomeie. Diz Frosh ${ }^{21}$ :

"o analista passa a ser responsável [...] pela possibilidade (ou impossibilidade) de reparação. A incapacidade de perceber, de reconhecer o sofrimento do sujeito, representa um novo episódio de violência, dessa vez por parte do analista".

A impossibilidade do analista de escutar o sofrimento do analisando resultaria "na perda daquele terceiro espaço em que a mudança seria possível". Em que pesem as questões transferenciais que se fazem presentes em um trabalho analítico, uma reedição do traumático em análise, especialmente por uma dificuldade de escuta do analista, pode ser brutal para $o$ sujeito que deseja ser escutado em sua dor. 
Uma das possíveis consequências iatrogênicas dessa escuta empobrecida seria uma relação transferencial sustentada em uma dinâmica sadomasoquista inconsciente, em que o analisando retorna ao setting para repetir o ciclo de agressões já familiar (sem conseguir, portanto, rompê-lo) e o analista repete o lugar do agressor.

Um trabalho de análise que permita ao analisando atravessar todo o processo de nomeação e simbolização de seu sofrimento criará condições para que ele se distancie de uma visão de si mesmo, tão colada ao olhar externo e construa outras maneiras de estar no mundo, inclusive na relação com seus diferentes, promovendo descargas pulsionais mais saudáveis do que a estagnação e apatia ou o ato imposto pela pulsão destrutiva, que de acordo, Ferenczi ${ }^{19}$ :

As intervenções dos analistas ajudam no processo de simbolização, para que não existam apenas condutas movidas pela vingança e pela punição desmedidas, condutas que levam às passagens ao ato, sem a mediação dos impulsos selvagens.

\section{CONCLUSÃo}

São inúmeros os discursos de ódio ao longo da história, que não parecem perder potência mesmo diante de uma realidade social em que são amplamente questionados e condenados. Muitas vezes, acredita-se que suas piores representações tenham sido superadas, apenas para vê-las ressurgir com potência redobrada no laço social. Essa persistência do discurso se encontra justificada nas hipóteses freudianas sobre os impulsos destrutivos inerentes ao ser humano, seus recursos de identificação e suas moções narcísicas.

A teoria psicanalítica traz à luz as origens do desejo humano de destruição e revela uma constatação indigesta: não é possível se livrar completamente desse desejo. 0 que se mostra viável por meio da psicanálise é a busca por saídas mais saudáveis a esses impulsos, identificações e motivações narcísicas, já que sua exacerbação é potencialmente causadora de adoecimento psíquico - além de poder culminar na real aniquilação desses tantos "outros".

As paredes dos consultórios dos psicanalistas são testemunhas da profundidade e complexidade das marcas inconscientes dos tipos de violências para suas vítimas. Assim, o negro ter consciência de que está sujeito a um sistema racista, o homossexual ter consciência de que é preterido por tradições sociais heteronormativas, ou a pessoa transgênero ter consciência da violência imposta pela normatividade cisgênero da cultura, e assim por diante, não basta para aniquilar o sofrimento oriundo das feridas psíquicas, pois sua natureza traumática só pode ser acessada por outras vias que não a da mera compreensão racional.

É aí que entra o papel de uma análise em que a escuta do analista não ignora esses fatores e abra espaço para a simbolização. Ademais, a transferência possibilita que o analista responda de um lugar outro, descolado do lugar-comum dos discursos traumatizantes e sintonizado à complexa miríade de representações, mecanismos de defesa, compulsões à repetição e outros processos psíquicos que respondem a essas violências - evidentemente singulares a cada sujeito, mas sem deixar de ter traços comuns.

Seria utópico se imaginar uma sociedade em que o ódio não figure como um dos operadores das relações humanas, especialmente por manter um vínculo íntimo com o amor, marcando sua ambivalência. Entretanto, a noção de que o ser humano possui uma disposição inata ao desejo de aniquilação do outro pavimenta o caminho para uma reflexão sobre como tal disposição se manifesta em sua vida, permitindo-lhe embarcar em um trabalho de explorar novos caminhos para seus mecanismos de defesa mais primários - caminhos esses que possibilitem uma existência menos devastadora e uma convivência com o outro que se sustente na alteridade.

Este estudo tem como limitações o reduzido número de pesquisas e reflexões acerca de fenômenos específicos de discurso de ódio com um recorte psicanalítico e, portanto, não sendo possível abarcar todas as zonas cinzentas que podem surgir acerca das manifestações e dos efeitos deste discurso. As proposições preliminares aqui apresentadas ainda podem ser 
desenvolvidas e aprofundadas para ampliar sua compreensão e prática. Por outro lado, esta revisão aponta a importância do tema e traz pistas para a prática psicanalítica.

\section{REFERÊNCIAS}

1. Freud S. O mal-estar na civilização. In: 0 mal-estar na civilização, Novas conferências introdutórias à psicanálise e outros textos (1930-1936). Souza PC, tradutor. São Paulo: Companhia das Letras; 2010.

2. Freud S. Psicologia das massas e análise do eu. In: Freud S. Psicologia e análise do eu e outros textos de 1920-1923. Souza PC, tradutor. São Paulo: Companhia das Letras; 2010.

3. Oxford Dictionaries. Hate speech. [Internet]. [citado em 10 nov 2018]. Disponível em: https://en.oxforddictionaries.com/definition/hate_speech

4. Mcgonagle T. The Council of Europe against online hate speech: conundrums and challenges [Internet]. In: Council of Europe Conference of Ministers Responsible for Media and Information Society; 2013; Belgrado, Sérvia. Amsterdã, Holanda: Institute for Information Law (IViR); 2013 [citado em 10 nov 2018]. p. 15. Disponível em: https://www.ivir.nl/publicaties/download/Expert_paper_hate_speech.pdf

5. Schafer G, Leivas PG, Santos RH. Discurso do ódio: da abordagem conceitual ao discurso parlamentar. Rev Inf Legislat. [Internet]. 2015 [citado em 10 nov 2018]; 52(207):143-58. Disponível em: http://www2.senado.leg.br/bdsf/item/id/515193

6. Brown NLM, Stentiford BM. The Jim Crow encyclopedia. Westport, CT: Greenwood; 2008.

7. Macagno L. Etnografia e violência no país do apartheid: dois relatos sobre a África do Sul. Hist Quest Deb. 2015 [citado em 27 out 2020]; 62(1)133-62. Disponível em: https://revistas.ufpr.br/historia/article/view/44150/26711

8. Ramón Mendos L. State-sponsored homophobia [Internet]. 13 ${ }^{\text {th }}$ ed. Geneva: ILGA; 2019 [citado em 12 nov 2019]. Disponível em: https://ilga.org/downloads/ILGA_State_Sponsored_Homophobia_2019.pdf

9. Freud S. Introdução ao narcisismo. In: Freud S. Introdução ao narcisismo: ensaios de metapsicologia e outros textos de 1914-1916. Souza PC, tradutor. São Paulo: Companhia das Letras; 2010. p. 13-50.

10. Freud S. Os instintos e seus destinos. In: Freud S. Introdução ao narcisismo: ensaios de metapsicologia e outros textos de 1914-1916. Souza PC, tradutor. São Paulo: Companhia das Letras; 2010. p. 75-6

11. Freud S. Além do princípio do prazer. In: Freud S. História de uma neurose infantil ("O Homem dos Lobos"), Além do princípio do prazer e outros textos. Souza PC, tradutor. São Paulo: Companhia das Letras; 2010. p. 161-239.

12. Green A. Narcisismo de vida, narcisismo de morte. Berliner C, tradutora. São Paulo: Escuta; 1988. p. 141-2.

13. Freud S. O eu e o id. In: O eu e o id, "autobiografia" e outros textos (1923-1925). Souza PC, tradutor. São Paulo: Companhia das Letras; 2011. p. 13-74.

14. Wahba LL. A estranheza do outro e os limites da tolerância. Junguiana [Internet]. 2017 [citado em 04 ago 2020]; 35(2):5-12. Disponível em: http://pepsic.bvsalud.org/pdf/jung/v35n2/02.pdf

15. Fulber VG. Retórica de ódio, cultura e pulsões. Estud Psicanál. [Internet]. 2019 [citado em 04 ago 2020]; 51:139-47. Disponível em: http://pepsic.bvsalud.org/pdf/ep/n51/n51a13.pdf

16. Nogueira IB. Cor e inconsciente. In: Kon NM, Silva ML, Abud CC, organizadores. 0 racismo e o negro no Brasil: questões para a psicanálise. São Paulo: Perspectiva; 2017. p. 121-6.

17. Pereira MLIEM. Faces da violência: trauma, exílio, luto, culpa. In: Ocariz MC, organizadora. Psicanálise e violência social. São Paulo: Escuta; 2018. p. 69-87.

18. Laplanche J, Pontalis JB. Vocabulário da psicanálise. São Paulo: Martins Fontes; 2001. 554p. 19. Ferenczi S. Análise de crianças com adultos. In: Ferenczi S. Psicanálise IV. São Paulo: Martins Fontes; 1992. p. 79-95. 
20. Ocariz MC. As contribuições da psicanálise diante dos efeitos da violência social. In: Ocariz MC, organizadora. Psicanálise e violência social. São Paulo: Escuta; 2018. p. 25-44.

21. Frosh S. Reconhecimento, desculpas e perdão entre os que "vêm depois". In: Ocariz MC, organizadora. Psicanálise e violência social. São Paulo: Escuta; 2018. p. 109-21.

Editora Associada: Fernanda Carolina Camargo.

\section{CONTRIBUIÇÕES}

Mariana de Toledo Nascimento Gomes foi responsável pela concepção, análise e redação e revisão.

\section{Como citar este artigo (Vancouver)}

Gomes MTN. 0 discurso de ódio na clínica psicanalítica. REFACS [Internet]. 2021 [citado em inserir dia, mês e ano de acesso]; 9(2):472-80. Disponível em: inserir link de acesso. DOI: inserir link do DOI

\section{Como citar este artigo (ABNT)}

GOMES, M. T. N. O discurso de ódio na clínica psicanalítica. REFACS, Uberaba, MG, v. 9, n. 2, p. 472-80, 2021. DOI: inserir link do DOI. Disponível em: inserir link de acesso. Acesso em: inserir dia, mês e ano de acesso.

\section{Como citar este artigo (APA)}

Gomes, M.T.N. (2021). O discurso de ódio na clínica psicanalítica. REFACS, 9(2), 472-80. Recuperado em inserir dia, mês e ano de acesso de inserir link de acesso. DOI: inserir link do DOI. 